\title{
Smart technology renders high-end manufacturing possible
}

\author{
Bing-Heng Lu
}

Received: 31 March 2013/Accepted: 21 May 2013/Published online: 19 June 2013

(c) Shanghai University and Springer-Verlag Berlin Heidelberg 2013

\section{Review of China's manufacturing industry}

Before Liberation, even such small items as nails and matches in China were all manufactured by foreigners, as a result, they were called "foreign nails" and "foreign matches". China's mechanical manufacturing capabilities picked up after the foundation of new China with the aid of the former Soviet Union. From 1960s onwards, the industry was mainly dependent on self-reliance. In 1978 China's higher education was resumed and universities began to enroll students. As a result of economic reforms and opening up, China's manufacturing industry began to learn from foreign examples, and launched the first wave of manufacturing for household electrical appliances between 1978 and 1987. During this period mechanical engineering and science also underwent rapid development. Professor Chongxian $\mathrm{Gu}$ at Xian Jiaotong University was one of the earliest scholars studying dynamics of machining tools. His research achievements attracted some world-renowned experts' (for example the famous Professor Tobias) attention and academic exchange with their Chinese partners. Professor Yushan Tan was invited to build the Machine Tool Laser Measurement Laboratory at the University of Birmingham. During the 1980s Hanhe Yang founded the "Mechanical Control Engineering", highly praised by Prof. Shuzi Yang, the academician of Chinese Academy of Engineering. His work was considered as the classic works of mechanical dynamics. Two alumni of Xian Jiaotong University namely Yansun Lu (former chief engineer and Deputy Minister of the Ministry of Mechanical Industry)

B.-H. Lu $(\bowtie)$

School of Mechanical Engineering, Xi' an Jiaotong University,

Xi'an 710049, People's Republic of China

e-mail: bhlu@mail.xjtu.edu.cn and Mr. Guobao Zhang, former Deputy Director of National Development and Reform Commission and Director of National Energy Administration. Both men had devoted their entire lives and energy to Chinese manufacturing industry, and earned the accolade of "Engineers of the Republic".

The second wave of manufacturing in modern Chinese history is automotive manufacturing (1987-1997). During this period of time, foreign manufacturers came to China in droves, and many privately-owned manufacturers began to sprout up. One must recognize that the astounding success in both waves of manufacturing in China-so successful are they that China is now the world's largest manufacturing nation-is mainly attributed to China's large population and cheap rural labor. It is important to note that the State "985" and "211" programs were aimed at developing world-class academic disciplines in key universities. After more than 30 years of development, China's manufacturing industry has become the largest in the world constituting $19.4 \%$ of the global manufacturing in 2010 (see Fig. 1). It expanded further to $19.8 \%$ in 2011. In many other products China's production volume also topped the world (see Table 1). Nevertheless at this point, China is only a large manufacturing nation but not a manufacturing power.

Aerospace manufacturing is the third wave for China's manufacturing industry. It represents a high level of manufacturing technology and indeed powers its development. Manufacture of large aircrafts, aircraft engines, rotor blades and turbine disc is an extremely difficult process, especially considering that they require materials such as high-temperature alloy and titanium alloy and that they possess curved surfaces. Nevertheless China's aerospace industry is beginning to move away from its early days and is moving towards becoming a full-fledged industry. 


\section{(\%)}

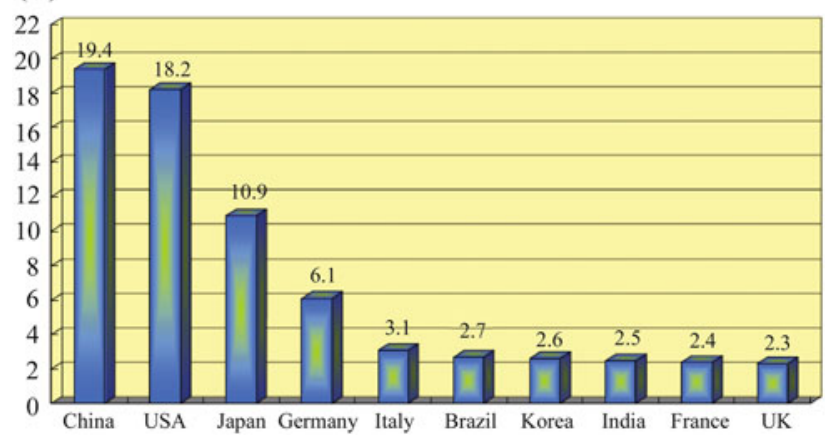

Fig. 1 Manufacturing production volume of major nations in 2011

During the National Innovation Conference in 2012, former Premier Wen Jiabao proposed to add "Designed in China" and "Invented in China" in addition to "Made in China". As such an excellent opportunity awaits China's aerospace industry. Following the production of Yun-20 transportation aircraft, the aircraft manufacturer carried out technological revamping that would cost well over RMB 2 billion-a fantastic opportunity for the manufacturing equipment industry. However China's manufacturing equipment remains to be at the low end and must be upgraded. At the same the industry is faced with intense international competition, particularly after the financial crisis developed nations have taken the view that greater attention should be given to their manufacturing industry. For example, the US has proposed "re-industrialization" by injecting high technology into manufacturing to create an advantage for the industry. Her idea is to "defeat" the concept of "Made in China" with a combination of "artificial intelligence, robots and digital manufacturing technology". In this regard 5 departments jointly studied and proposed 20 technologies which they thought would revive American manufacturing. The first was 3D printing, and the second was robotics, and so on. During the past one year alone President Obama mentioned on no less than 5 different occasions, measures that would reinvigorate American manufacturing industry (see Table 2). In fact, the
Table 2 America's plan for development of advanced manufacturing industry

\begin{tabular}{|c|c|}
\hline Date & Steps \\
\hline April 2009 & $\begin{array}{l}\text { President Obama first proposed the idea of } \\
\text { revitalizing manufacturing industry in a speech } \\
\text { at Georgetown University }\end{array}$ \\
\hline December 2009 & $\begin{array}{l}\text { President Obama signed "A Framework for } \\
\text { Revitalizing American Manufacturing" }\end{array}$ \\
\hline August 2010 & $\begin{array}{l}\text { President Obama signed into Act the U.S. } \\
\text { Manufacturing Enhancement Act of } 2010\end{array}$ \\
\hline June 2011 & $\begin{array}{l}\text { The President's Council of Advisors on Science } \\
\text { and Technology submitted a report entitled } \\
\text { "Ensuring Leadership in Advanced } \\
\text { Manufacturing" to President Obama, following } \\
\text { which President Obama announced the } \\
\text { "Advanced Manufacturing Partnership" }\end{array}$ \\
\hline February 2012 & $\begin{array}{l}\text { The National Science and Technology Council } \\
\text { announced "A National Strategic Plan for } \\
\text { Advanced Manufacturing" }\end{array}$ \\
\hline
\end{tabular}

EU, Japan and UK all launched similar strategic development plans; they even thought that a revolution in manufacturing technology and manufacturing equipment would spur a third industrial revolution, notwithstanding its different interpretations, e.g. that of the energy ministry which referred to network plus energy and distributed new energy. One thing is certain in everybody's mind: The previous two industrial revolutions were closely related to production mode and production equipment.

\section{Smart technology renders high-end manufacturing possible}

\subsection{Development history of manufacturing equipment}

It must be said that the use of smart technology in high-end equipment is an excellent matter. In the "Exploitation of the Works of Nature" there is a picture of a horse-drawn water mill being used to carry out 'milling'. There are also signs of

Table 1 Production volume of China's manufacturing industry for key products

\begin{tabular}{lccr}
\hline Product name & 2009 Production volume & 2010 Production volume & 2011 Production volume \\
\hline Raw steel $/\left(10^{4} \mathrm{t}\right)$ & 57,218 & 62,696 & 68,388 \\
Color TV $/ 10^{4}$ & $9,898.8$ & $11,830.0$ & $12,231.4$ \\
Computer $/ 10^{4}$ & $18,215.1$ & $24,584.5$ & $32,036.7$ \\
Programmed controlled exchange $/ 10^{4}$ & $4,152.5$ & $3,138.3$ & $3,034.0$ \\
Mobile phone $/ 10^{4}$ & $68,193.4$ & $99,827.4$ & $113,257.6$ \\
Automobiles $/ 10^{4}$ & $1,379.5$ & $1,826.5$ & $1,841.6$ \\
Power generator/(10 $\mathrm{W})$ & 11,994 & $12,264.2$ & $13,998.7$ \\
Metal cutting machine tools $/ 10^{4}$ & 58.6 & 75.6 & 86.0 \\
Large and medium tractor $/ 10^{4}$ & 37.1 & 38.3 & 40.2
\end{tabular}


'milling' on the Terracotta warriors in Xian. However, a curious and bewildering fact is that 2000 years ago there was no electrical machinery. As a result of the invention of the electric motor during the Industrial Revolution, the processing equipment was transformed into machine tools. With the advent of information technology, the computer was incorporated with machine tools to give us numerically controlled machine tools. However a problem with numerically controlled machine tools was that they carried out machining according to pre-set program. In a wider sense the machining is also design, since it is carried out according to pre-designed tool path. In reality, there are numerous possibilities during machining process since all cutting tools will eventually experience wear-and-tear, and there are different vibration characteristics for different positions. Moreover the cutter bar's axis may experience thermal expansion during machining, and the machined parts have different thickness at different positions. In addition, we should also consider the fact that deformation under static force is different from vibration under dynamic force. Thus, component parts machined by fixed programs would not possess the necessary quality, and would have a reduced accuracy. This presents a question facing us: would smart technology such as artificial intelligence that could interfere the machining process, be capable of reaching the best machining state in order to maintain the highest cutting efficiency? Put it another way, "intelligent manufacturing equipment $=$ equipment + sensor + software for optimization of technique". For manufacturing equipment, perhaps this is even more appropriate than the traditional formula of "robots + numerically control". That would obviously mean that the equipment possessing evaluation, analysis, deduction, decision-making and control functions would be required, and considerations should also be given to sensors and intelligent control software (see Fig. 2).

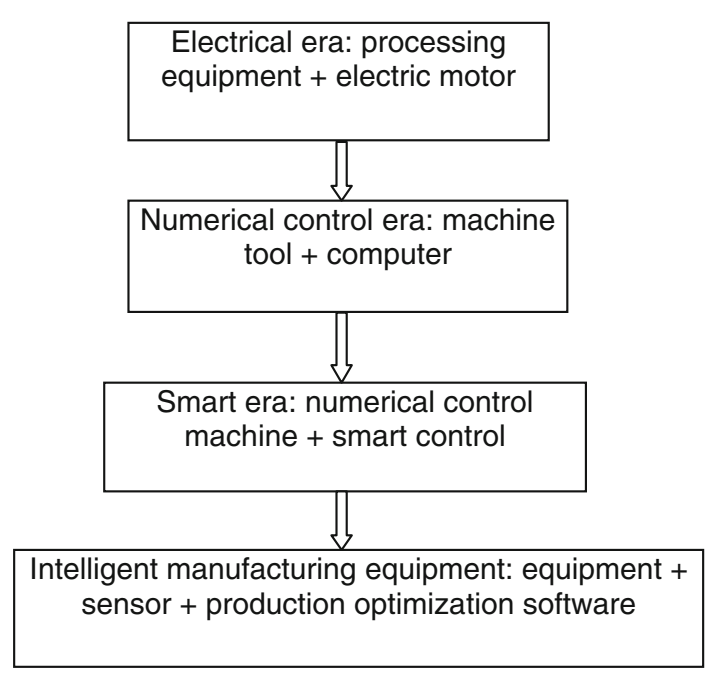

Fig. 2 Development history of manufacturing equipment
Numerical control technology involves processing workpieces according to pre-set programs; it is incapable of responding to operation variables during processing. Intelligent manufacturing equipment, however, possesses sensing, analyzing, deducing, decision-making and control functions, combining manufacturing technology, information technology and intelligent technology. Sensors and intelligent control software are integrated in the equipment in order for the latter to achieve optimized workmanship by adapting to the manufacturing environment and process.

\subsection{Increasing speed and precision of equipment through smart technology}

High-speed machines possess great advantages during machining, e.g., little cutting and shearing forces as well as small deformation under stress. Today, cutting of large turbine blades is made possible only with high-speed cutting machines. These machining equipment have the advantages of greater efficiency and assured machining quality.

The thickness of an aircraft's floor panel is only $1 \mathrm{~mm}$, with as much as $95 \%$, sometimes even $97 \%$, of the materials being cut off, thus presenting the need for highspeed machine tools. However the cutting blades for highspeed machining are extremely expensive and they cannot undergo abrupt changes with respect to their stress conditions. In fact, regardless of the direction and force of cutting, any changes would have to be smooth and steady. This poses considerable difficulty during programming since the workpieces to be machined are quite different. If smart technology were to be used, it would be possible to constantly monitor changes in the cutting force and hence achieve excellent control as well as reduce the reliance of programmer on the knowledge of cutting, machining and cutting blades.

Ultra-precision machining also requires error compensation. Inspection needs to be carried out to check for variables in the machining process due to changes in the operation environment, before error compensation can be undertaken. This also applies to existing thermal processing equipment. Processing used to be fairly simple as it involved the manufacturing of semi-finished products. Ultimately quality could not be assured for such products and as semi-finished products they had to undergo heat treatment. A gear factory in Nantong, Jiangsu Province produces extremely good gears, with $70 \%$ of its products being exported. The factory invested more than 100 million $\mathrm{RMB}$ in a smart-control heat treatment system which ensured the quality of gears undergone heat treatment. As a result the factory is able to maintain high degree of accuracy for its milled products. Nowadays aerospace manufacturing techniques no longer merely require excellent 
positional accuracy through machining center during machining process. Instead manufacturing efficiency or quality of component parts has to be assured through thermal processing. So numerous sensors are required during the monitoring and control process.

\subsection{Value of smart technology}

Smart technology would have to be used in order to raise the efficiency of high-speed machines and allow them to achieve the best cutting conditions. At present the best usage rate for $\mathrm{NC}$ machine is only $10 \%-15 \%$, even for imported machines. One of the main reasons is the lack of knowledge on process optimization, cutting tools and materials. The other main reason is that many people are unable to cope with multi-faceted operations. For example, component parts are different from each, making it difficult for operators to have full grasp of considerable variety of operations. Thus people hope to raise the machine's efficiency to $50 \%$ through smart technology; in this way, one machine would be equivalent to two or even three units.

As we have stepped into the nano-era from the microera, accuracy cannot be assured using only manufacturing technology. Indeed, measurement technology allows processing accuracy to be the same as measurement accuracy. Furthermore measurement accuracy is higher than machining accuracy by roughly two orders of magnitude.

Smart technology can also greatly enhance the technological added value for machine tools. At present machine tools made in China cost $1 / 2-2 / 3$ of those made overseas. An example is Greensen Gear Milling Machine Tool which costs roughly three times those made domestically. Its turbine blade processing software costs USD 350,000 per set and is still under an embargo against China.

\subsection{Examples of intelligent manufacturing equipment}

Intelligent manufacturing equipment is a rising trend overseas:

(i) DMG smart machine tools with Power Tools software pack.

(ii) GF AgieCharmilles high-speed cutting and processing center is capable of monitoring and setting levels according to speed during processing.

(iii) GF AgieCharmilles/Mikron smart machine tools are capable of choosing between speed priority, surface roughness priority, precision priority or compromised target.

(iv) Okuma smart machine tools are designed with "thermo-friendly concept" which allows the machine tool's temperature to be evenly distributed, thus ensuring processing precision. The machine tool also possesses processing guide function

(v) BUHLER smart high-integrity casting equipment can ensure high precision.

(vi) SCHULER stamping production line is now operated by smart technology.

\section{Suggestions on development for intelligent manufacturing}

(i) Formulate development path.

(ii) Focus on development of sensors, since for machine tools to be equipped with smart technology they would require suitable sensors. Sensors play a very important role in the machine tools' performance. Thus the government should support their development.

(iii) Conduct in-depth research in optimization of workmanship, i.e. research on the characteristics of machine tools. For example, with respect to "contrology" only measurement is required for the entire system. The measured values and target values are then compared in order to determine a control strategy. Obviously one is not required to be thoroughly acquainted with processing and manufacturing system in order to understand issues such as the system's limits or whether volatility would be induced or the manner in which response speed is followed, etc. and achieve good smart control.

(iv) Focus should be given to aerospace industry and give priority to high-end machine tools. They should include high-speed machining centers, machine tools for aircraft's large flexible structural parts; ultraprecision machine tools, machine tools for optical lens; five-axial machining center, turbine blade machining machine tools; high-strength machine tools-machine tools for difficult-to-cut aerospace materials; smart forging press: additive manufacturing (3D printing) equipment.

(v) "Innovation-led" development

(1) To achieve smart technology one would have to innovate. For example, the "Ni Zhifu" drills are significant innovations. Innovation also requires scientific summary and verification from experiments before it can be promoted. After Professor Wu Xianming found the "Ni Zhifu" drill in China, he brought the semi-finished products to the United States. With the sponsorship of Natural Science, as well as participation of Chinese scholars, Professor Wu took great pains and considerable perseverance to 


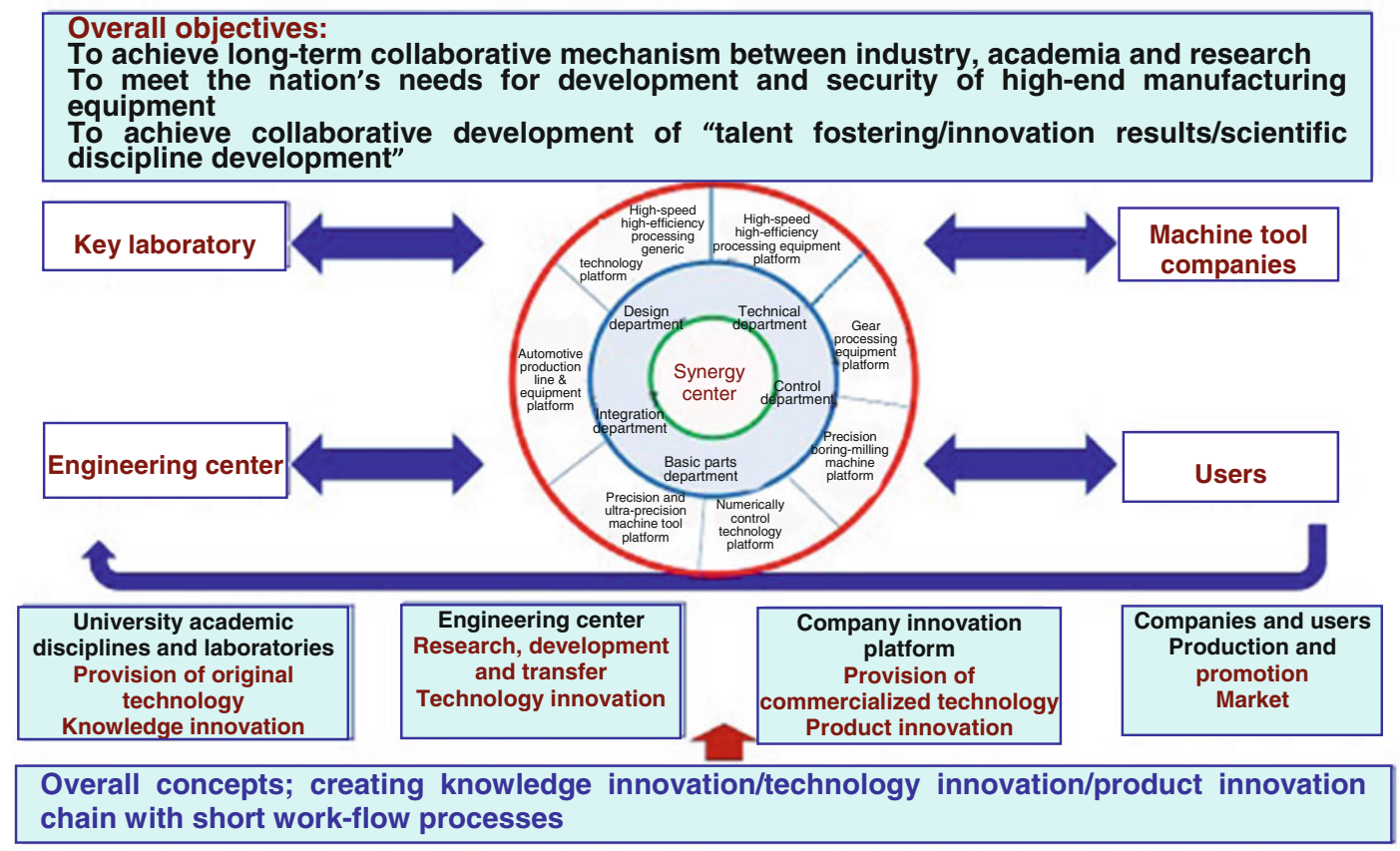

Fig. 3 Collaborative innovation center for "high-end manufacturing equipment"

invent the first-generation purely-mechanical blade sharpening machine, followed by a digital-display version. With the advent of numerical control the technology was applied to vehicles made by the Big Three Automobile manufacturers-it took a mere $0.1 \mathrm{~s}$ to drill a $10 \mathrm{~mm}$-hole on a $10 \mathrm{~mm}$ aluminum alloy plate.

(2) A major invention of the automotive engine released last year was the gear transmission which was added to it. The speeds of the front and back gears now become different and the engine's efficiency is significantly increased. It took American automotive companies decades of study in order to make the idea practicable since it involved numerous issues, including materials and workmanship, not to mention voluminous verification work.

(3) A positive side-effect for China in relation to intelligent manufacturing equipment is the potential to expand cloud computation and cloud manufacturing in what is popularly known as cloud manufacturing era. The former are capable of fostering the nation's spirit of innovation. In the cloud computation era, an individual's insights can be developed 'in the clouds'. By integration through assessments, a company can in short order apply the public's wisdom to improve intelligent manufacturing equipment. Such endeavor requires everyone's effort; it cannot be solved by only a few people.

(vi) Collaborative innovation for "high-end manufacturing equipment"

Global competition in manufacturing will be more intensive and cruel in the future. This signifies both optimistic and worrying future for China. In order to truly become a manufacturing nation, China needs to lay a strong industrial foundation in such areas as materials preparation, basic component parts, precision measurement and reliability. The state government needs to promulgate policies in support of the upgrading of the manufacturing industry, as well as increase its investments in scientific research. It should also improve the environment for scientific research and innovation. Given that cloud computation has made the public's wisdom available for the industry, the governmental departments at all-levels should leverage on this advantage and be actively involved in various innovative organizations such as companies, higher educational institutions and achieve collaborative innovation in high-end manufacturing equipment (see Fig. 3). 